\title{
Corpus Delicti Exam on Cat (Felis Catus) Victim of Firearms caused Wounds- Case Report
}

Tália Missen Tremori, Isabela Emy Kamiguchi, Bárbara Wagner Duarte Ferraz de Camargo, Mara Rita Rodrigues Massad, Laila Massad Ribas and Noeme Sousa Rocha

UNESP - Univ Estadual Paulista, Brazil

*Corresponding author: Tália Missen Tremori, Department of Veterinary Clinic, Campus Botucatu, UNESP - Univ Estadual Paulista, Brazil, Tel: +55(14)99827-7318; Email: talia_missen@hotmail.com

Received date: December 19, 2016; Accepted date: February 14, 2017; Published date: February 17, 2017

Copyright: ( 2017 Tremori TM, et al. This is an open-access article distributed under the terms of the Creative Commons Attribution License, which permits unrestricted use, distribution, and reproduction in any medium, provided the original author and source are credited.

\begin{abstract}
Maltreatment against animals is defined as a deliberated action that causes pain and suffering to those. At this range, Brazilian law of Environmental Crimes states that cruelty against animals is, by nature, a crime. In cases of suspected maltreatment and non-accidental injury, is of great importance the role of the veterinary doctor in recognizing and, therefore, taking the correct conduct during the attendance. For this, one must have the knowledge of the elements that sustain the chance of abuse, as the characteristics of the wounds and whether they consist with the record given by the owner, if the wounds repeat in this animal or in other animals of the household, the posture of the owner during the attendance, amongst others.
\end{abstract}

Keywords: Maltreatment; Environmental crimes; Projectile

\section{Introduction}

According to the Legislation laid down in Art. 32 of the Environmental Crimes, Law 9.605/98, to inflict act of abuse, hurt or mangle upon wild animals, domestic or domesticated is considered a crime implying in 3 months to 1 year of penalty and fine. The presence of bodily injury in animals can be framed as maltreatment and can shape as a crime. According to Lockwood \& Arkow (2016), animal maltreatment is often related to a complex network of domestic violence, including personality disorders in children and teenagers. Statistics show that in Brazil, cats are the primary target for abuse, which could be related to its body shape and behavioral characteristics. With this, it is clear that the veterinary doctor has an important part in these situations, since discovering elements that can show signs of maltreatment to the case closure.

Research by Munro and Thrusfield (2012) shows that a combination of several factors helps to rise suspicion and determine a maltreatment case. The main factors quoted are: suspicion by the own caretaker regarding an aggressor; domestic violence records; records inconsistent with the injuries found; incomplete records; owner and animals' posture during the attendance; type of injury found; repeatability of the injuries in different periods of time; other animals from the same household who also showed body injury or died; and socioeconomic situation of the owner. Therefore, it is interesting that the Veterinary Doctor can use this knowledge to guide the owner and authorities leading to a correct treatment to the victimized animal, once the injury is characterized upon its nature and extension, it is fundamental for the correct management and treatment of those.

Wounds caused by projectile can be considered to be criminal, and, therefore, one must know the legal aspects that protect these cases, meeting in this range the importance of Forensics Veterinary Medicine. Notions as ballistics can have a great contribution to the attendance of firearms injured animals, once the projectile characteristics, the kinetics absorbed with the impact and the tissue hit can determine the severity of the wound. The projectile wounded animal attendance starts with a traumatized animal approach (stating its clinical state, medical priority and prognostics), followed by an approach directed to each organ and damaged tissue, after the patient's stabilization.

\section{Case Report}

Cat, three years, male, castrated, after being rescued by its owner from the streets, for it had escaped 2 days ago, was analyzed and verified the presence of incised-stab wounds on right thoracic member and claudication (Figure 1A). At the clinic exam, the animal showed normal parameters. During the orthopedic exam stated the presence of crackling, at the radiographic exam it was possible to check radiopaque substance, between the tissues and in the bones (radius and ulna) too (Figure 2). The surgical intervention was successful, where it was done and the animal post-op follow up for the next 10 days until discharged, who recovered successfully (Figure 1B).
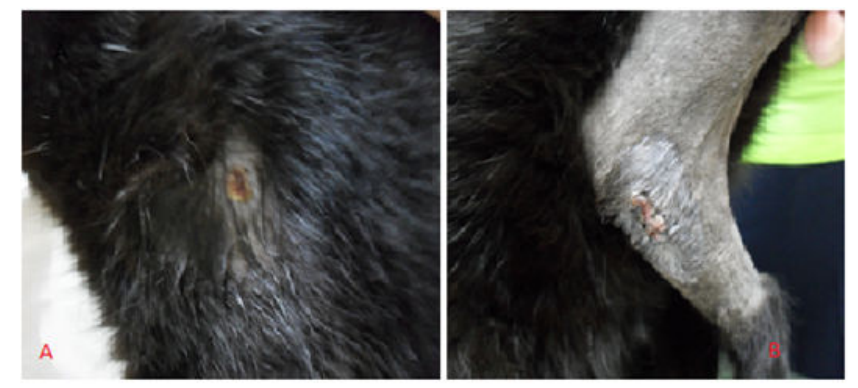

Figure 1: Cat, right thoracic member A: Entrance hole, caused by firearm projectile; B: Lesion after successful surgery to remove projectiles. 


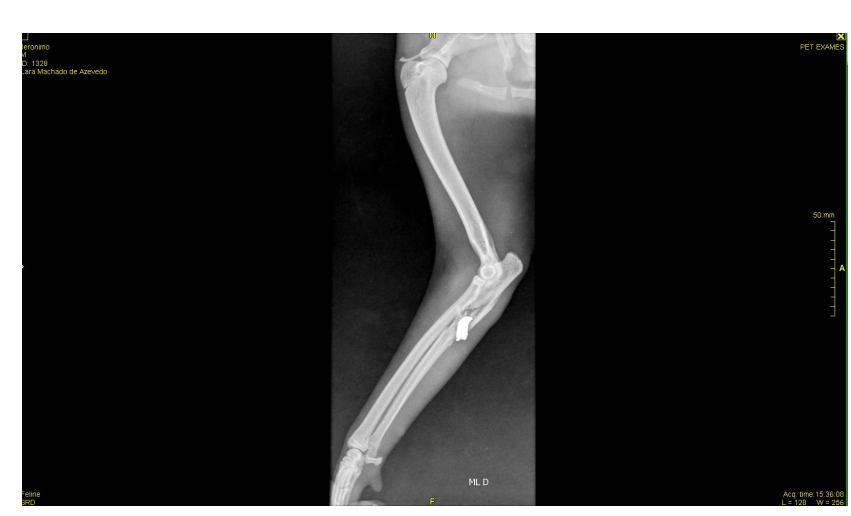

Figure 2: Radiographic exam, cat, right thoracic member in mediolateral position. Complete oblique fracture in ulna proximal region and radiopaque substance (meandering bullet) between bone injuries.

\section{Discussion}

Cats are pets with peculiar habits and it is up to the owner the responsibility to keep and care for those, as the law refers (omission of care of animals), where shapes as a crime the inadequate possession of those.

The matter could even extent to responsible animal ownership. However the paper's goal is to alert to the importance of the recognizing of wounds and to relate them with Forensics Veterinary Medicine, since those must be evaluated to identify whether the case refers to a crime or just an accident.

Often it is usual that general population discuss about maltreatment, and other kinds of crimes against animals, overall the domestic cat are historically victims of this cruel situation.

The injuries found on the animal corroborate with the firearm's projectile caused injury, and therefore the Brazilian legislation, Law 9.605, Art. 32, inflicting act of abuse, maltreatment, hurting and mangle animals is crime, where in this case should be charged to a police authority so it can be filed an accident report and afterwards establishment of a police inquiry, searching to find the responsible for the act.

The Veterinary Doctor's role in those cases is to guide the animal's caretaker, so they can take this kind of conduct and supply document with information that could help with the judicial process, in other words, a report through examination of the corpus delicti that will qualify according to forensic traumatology the kind of injury found.

Many of these knowledges are expanding and few are advertised by veterinary doctors, many of these information are extrapolated within human forensics medicine, which is a science consolidated many years ago and searches for an intersection between right and justice.

\section{Conclusion}

Animal abuse is considered crime laid down by the law 9.605/98, which amongst domestic animals cats are the most stricken. It is essential the veterinary doctor's right judgements, upon the factors that corroborate to the suspicion of the crime, as well as legal aspects that the situation implies, adopting the correct conduct. Diverse may be the nature of non-accidental injury, being provoked by projectiles constituted by similar characteristics. The animal, in this case, can be fatally harmed, which also highlights the importance of professional's technical knowledge to the right attendance for the patient. Having this framed, it is reasonable to assert that the knowledge surrounding maltreatment and its legislation and wounds by projectile (as well as subjects that imply this kind of trauma) must be spread among the veterinary doctors and used within the Human Medicine.

\section{References}

1. Bartlett CS (2003) Clinical update: Gunshot wound ballistics. Clin Orthop Relat Res 408: 28-57.

2. Baumgaertner H, Mullan SM, Main DCJ (2016) Unnecessary suffering by veterinary experts. Veterinary Record 179: 307.

3. Byers CG (2014) Missile injuries (gunshot wounds). In: M. McMichael. Handbook of canine and feline emergency protocols, (2nd edn) Wiley Blackwell, Lowa, USA.

4. Cooper JE, Cooper ME (2008) Forensic veterinary medicine: a rapidly evolving discipline. Forensic Sci Med Pathol 4: 75-82.

5. Degue S, Dilillo D (2009) Is animal cruelty a "red flag" for family violence? Investigating co-occuring violence towards children, partners, and pets. J Interpers Violence 6: 1036-1056.

6. Finnie JW (2016) Forensic Pathology of Traumatic Brain Injury. 53: 962-978.

7. Garzotto CK (2015) Wound management. In: Silverstein DC and Hopper $\mathrm{K}$, Small animal critical care medicine, (2nd edn). Elsevier Saunders, Missouri, USA.

8. Gerdin JA, Mcdonough SP (2013) Forensic pathology of companion animal abuse and neglect. Vet Pathol 50: 994-1006.

9. Lockwood R, Arkow P (2016) Animal Abuse and Interpersonal Violence: the cruelty connection and its implications for Veterinary Pathology. Vet Pathol 53: 910-918.

10. Mcdonough SP, Gerdin J, Wuenschmann A, Mcewen BJ, Brooks JW (2015) Illumiating dark cases veterinary forensic pathology emerges. Vet Pathol 52: 5-6.

11. Munro R (1998) Forensic necropsy. Semin Avian Exot Pet Med 7: 201-209.

12. Munro HMC, Thrusfield MV (2012) Battered pets: sexual abuse. J Small Anim Pract 42: 333-337.

13. Newbery SG, Cooke SW, Martineau HMA (2016) Perspective on Veterinary Forensic Pathology and Medicine in the United Kingdom. Vet Pathol 53: 894-897.

14. Olsen LE, Streeter EM, DeCook RR (2014) Review of gunshot injuries in cats and dogs and utility of a triage scoring system to predict short-term outcome: 37 cases (2003-2008). Journal of the American Veterinary Medical Association 245: 56-61.

15. Pollanen MS (2016) The rise of forensic pathology in human medicine: lessons for veterinary forensic pathology. Vet Pathol 53: 878-879.

16. Rocha NS (2015) Criminal Investigation. In: Jericó MM, Kogika MM, Andrade-Neto JP Textbook of Veterinary Internal Medicine, Roca, Rio de Janeiro, Brazil 2: 2261-2262.

17. Tremori TM, Rocha NS (2014) The examination of the corpus delicti in veterinary expertise. Journal of Continuing Education in Animal Science of CRMV-SP 11: 30-35. 